\title{
De la urgencia a la solidaridad. Acciones de visibilidad y apoyo al estallido social en Chile
}

\author{
Melina Jean Jean \\ Instituto de Investigaciones en Humanidades y Ciencias Sociales (UNLP-CONICET), Argentina \\ melinajeanjean@gmail.com
}

\section{Solidaridad activa con el pueblo de Chile. Primera Jornada de acción urgente}

“¡No son 30 pesos son 30 años!” fue el nombre seleccionado para la primera intervención de visibilidad y solidaridad con el pueblo de Chile, que tuvo lugar el 1 de noviembre de 2019 en el patio central de la Facultad de Humanidades y Ciencias de la Educación (FaHCE, UNLP). La convocatoria estuvo a cargo de la Maestría en Historia y Memoria, la revista Aletheia, la Prosecretaría de Derechos Humanos (FaHCE), el Programa Interinstitucional de Estudios sobre Memorias, Migraciones, Exilios y Refugios (PIEMMER) y el Equipo de Investigación "Del tercer gobierno peronista a la dictadura de 1976. La eliminación del tiempo bifronte. La ofensiva reaccionaria”. El título de la jornada alude a una consigna muy importante que se viralizó durante las primeras semanas y explica el motivo inicial del estallido que a continuación reponemos para contextualizar la emergencia de nuestras acciones.

El 4 de octubre de 2019 el gobierno de Sebastián Piñera anunció una suba de 30 pesos en las tarifas del transporte público (servicios RED, Metro y Tren Central) que se efectivizaron dos días después en Santiago, la capital. El 7 de octubre, un grupo de estudiantes secundarios del Instituto Nacional, en su pleno ejercicio del derecho a la protesta social, evadió el Metro de Santiago en la estación Universidad de Chile. Acción que se repitió durante los siguientes días con mayor grado de organización a través de las redes sociales y número de manifestantes. El 17 de octubre ocurrió la primera intervención violenta de Carabineros dentro del Metro, que para entonces contaba con la mayoría de sus servicios suspendidos, y que culminó con varias detenciones y destrucciones de sus instalaciones. El 18 de octubre es considerado el inicio del estallido social, ya que a las manifestaciones en el Metro (suspendido el servicio en su totalidad) se sumaron protestas en las calles y cacerolazos en distintos puntos de la ciudad. La respuesta del presidente fue decretar el Estado de Emergencia y posteriormente el toque de queda, delegando el intento de control de la situación a manos del Ejército de Chile. De hecho, Piñera declaró el 20 de octubre que el país estaba "en guerra contra un enemigo poderoso e implacable" ("Estamos en guerra", 21/10/19). Su intento de apaciguar la situación con la marcha atrás en la suba de las tarifas del transporte, no prosperó. Pues claro, como dice la consigna, ya no se trataba de 30 pesos. El estallido de rebeldía -ya en todo el país- denunciaba la crisis de más de 30 años de devastadoras consecuencias del sistema neoliberal instaurado durante la dictadura de Pinochet (1973-1990). La imagen ficticia de Chile como el "oasis con una democracia estable" de América Latina, tal como Piñera lo definiera, se hizo añicos (Monzón, 20/10/19).

A pesar de la censura y la manipulación de los grandes medios hegemónicos chilenos, la criminalización de las protestas y la brutal represión por parte de carabineros y militares, miles de chilenos y chilenas a lo largo y ancho del país lograron mostrar sus realidades, expresar su hartazgo, luchar, resistir y exigir la atención de sus demandas al gobierno ${ }^{1}$. Sin embargo, a estos reclamos iniciales se sumaron la urgencia y necesidad de denunciar las violaciones a los derechos humanos que el Estado chileno, a través de su brazo armado, ejecutaba día a día en las represiones a cada movilización. Para ello, hubo una herramienta que se destacó -y no es nueva en la proliferación de movimientos sociales insurreccionales en América Latina y el resto del mundo- pero 
en el caso chileno ha sido abrumador su despliegue y fundamental para la batalla de sentidos al interior del propio país y a escala internacional: la gestión estratégica de la visualidad que articularon las manifestaciones, sus demandas, la represión y las violaciones a los derechos humanos (Jean Jean, 2019).

Fueron las producciones visuales y audiovisuales emergidas desde Chile las que nos inspiraron a darle forma a la primera jornada de acción. Sin embargo, también contamos con nuestros propios antecedentes, pues no es la primera vez que desde el espacio académico de la Maestría en Historia y Memoria activamos este tipo de intervenciones desde la urgencia y sobre coyunturas que nos exigen acciones en lo inmediato. Así lo hicimos en el 2014 por los 43 estudiantes desaparecidos de Ayotzinapa, México, con la consigna “ iSomos estudiantes, somos Ayotzinapa!"2, y en el 2015 por las 41 niñas fallecidas en el incendio del "Hogar Seguro, Virgen de la Asunción" en Guatemala, con la consigna “iNo fue el fuego, fue el Estado!” ${ }^{3}$. En el 2019 no sólo en Chile ocurrieron movilizaciones masivas, también casi contemporáneamente ocurrieron en Ecuador, Colombia, Bolivia y otros países latinoamericanos. La represión de los gobiernos a tales manifestaciones, fue la respuesta común en todos los casos. El 20 de noviembre de ese mismo año, lxs numerosxs estudiantes colombianxs de la Maestría, se organizaron para realizar una jornada en apoyo al paro nacional en su país y en repudio, entre otras demandas, a todxs lxs líderes sociales, campesinos e indígenas asesinadxs y Desaparecidxs ${ }^{4}$.

En esta suerte de colectiva activista-académica, donde principalmente lxs estudiantes, docentes y directivxs ofician de promotorxs y organizadorxs de las intervenciones, los lenguajes artísticos han sido los recursos privilegiados para desarrollar dispositivos visuales para la acción. En la primera jornada por Chile entonces, el repertorio de herramientas fue el siguiente: por un lado, para reforzar el título de la convocatoria (Imagen 1), la consigna "No son 30 pesos son 30 años" fue realizada a modo de cartel con letras y números individuales - pintados con los colores de la bandera chilena- para que cada persona portara una letra o número y así formasen de manera colectiva la frase completa (Imagen 2).

\section{IMAGEN 1}

“iNo son 30 pesos, son 30 años!” flyer de la primera jornada de visibilización y solidaridad con Chile, 1 de noviembre de 2019, FaHCE, UNLP, Ensenada, Buenos Aires, Argentina.

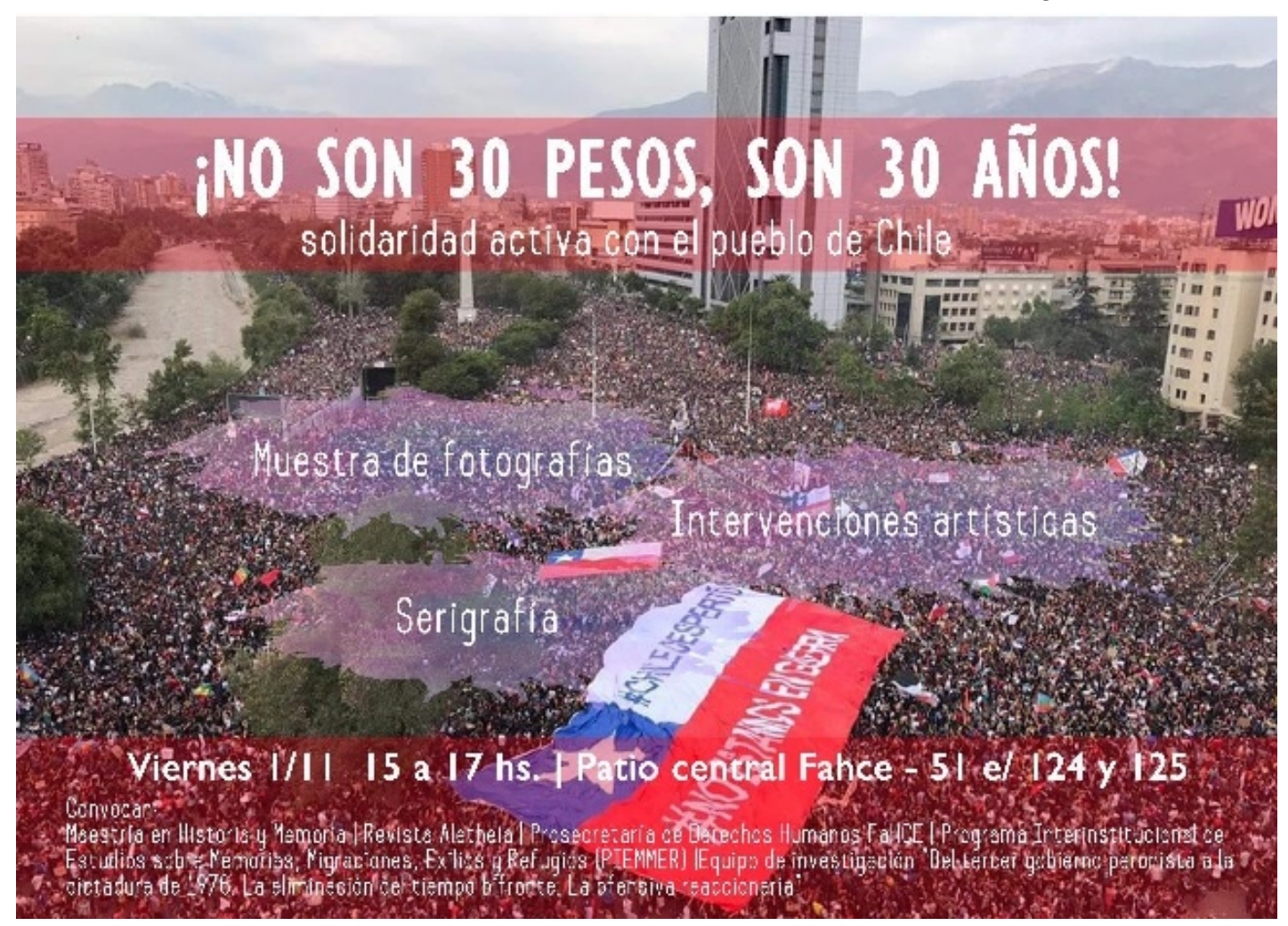

Convocaron: Maestría en Historia y Memoria, Revista Aletheia, Prosecretaría de Derechos Humanos (FaHCE), Programa Interinstitucional de Estudios sobre Memorias, Migraciones, Exilios y Refugios (PIEMMER) y el Equipo de Investigación "Del tercer gobierno peronista a la dictadura de 1976. La eliminación del tiempo bifronte. La ofensiva reaccionaria”. Diseño: Emilia Nieto. 


\section{IMAGEN 2}

Cartel con letras y números individuales. Primera Jornada de visibilidad y solidaridad con Chile, patio central de la FaHCE, UNLP, 1 de noviembre de 2019, Ensenada, Buenos Aires, Argentina.

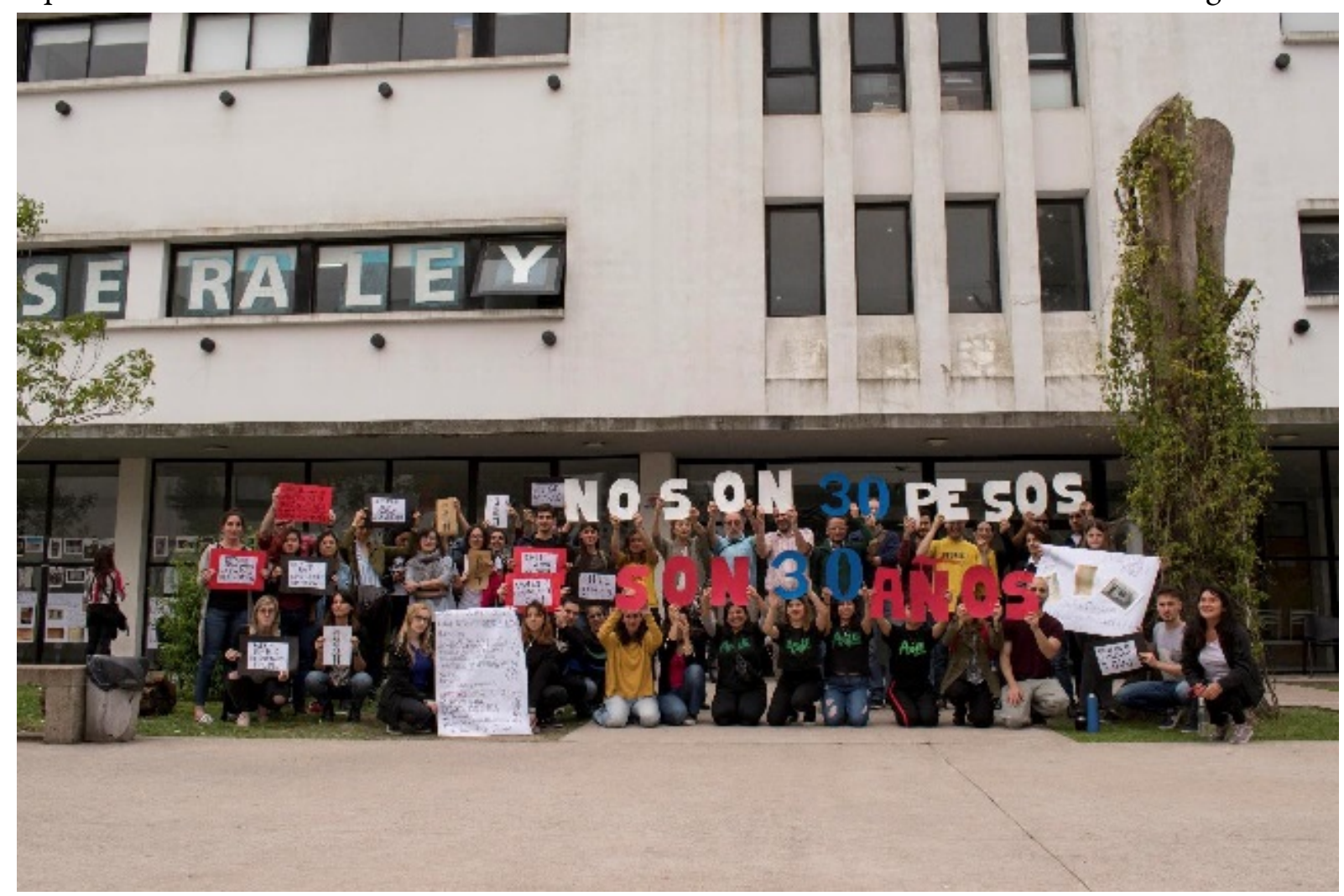

Fuente: Ana Sol Alonso

Por otro lado, unos días previos a la jornada, la Maestría lanzó una convocatoria virtual para que compañerxs, ex estudiantes y graduadxs de diferentes ciudades de Chile, nos enviaran fotografías tomadas por ellxs durante las movilizaciones, y algunas reflexiones o referencias sobre las mismas. El material que llegó fue impreso y exhibido durante la jornada en los ventanales del edificio B de la FaHCE (Imagen 3). Además, desde el Facebook de la Maestría se difundió un álbum con la compilación de las imágenes y textos de lxs autorxs 5 . Por otra parte, las artistas "de la casa" Florencia Basso y Emilia Nieto, una vez más nos acompañaron con sus diseños para serigrafías: "Chile despertó" (Imagen 4) y "No son 30 pesos son 30 años" (con una ilustración que sintetiza mediante figuras simbólicas, el movimiento popular chileno y la represión) (Imagen 5). Esta técnica de grabado posibilitó que lxs participantes, con la guía de las serigrafistas, hicieran sus propias impresiones en distintos soportes (Imagen 6). Además de esto, hubo producciones de carteles con información sobre los reclamos y las denuncias de violaciones a los derechos humanos (Imagen $7,8$ y 9$)$. 


\section{IMAGEN 3}

Exhibición de fotografías tomadas durante las movilizaciones por compañerxs, graduadxs y estudiantes chilenxs de la Maestría en Historia y Memoria y el Doctorado en Historia.

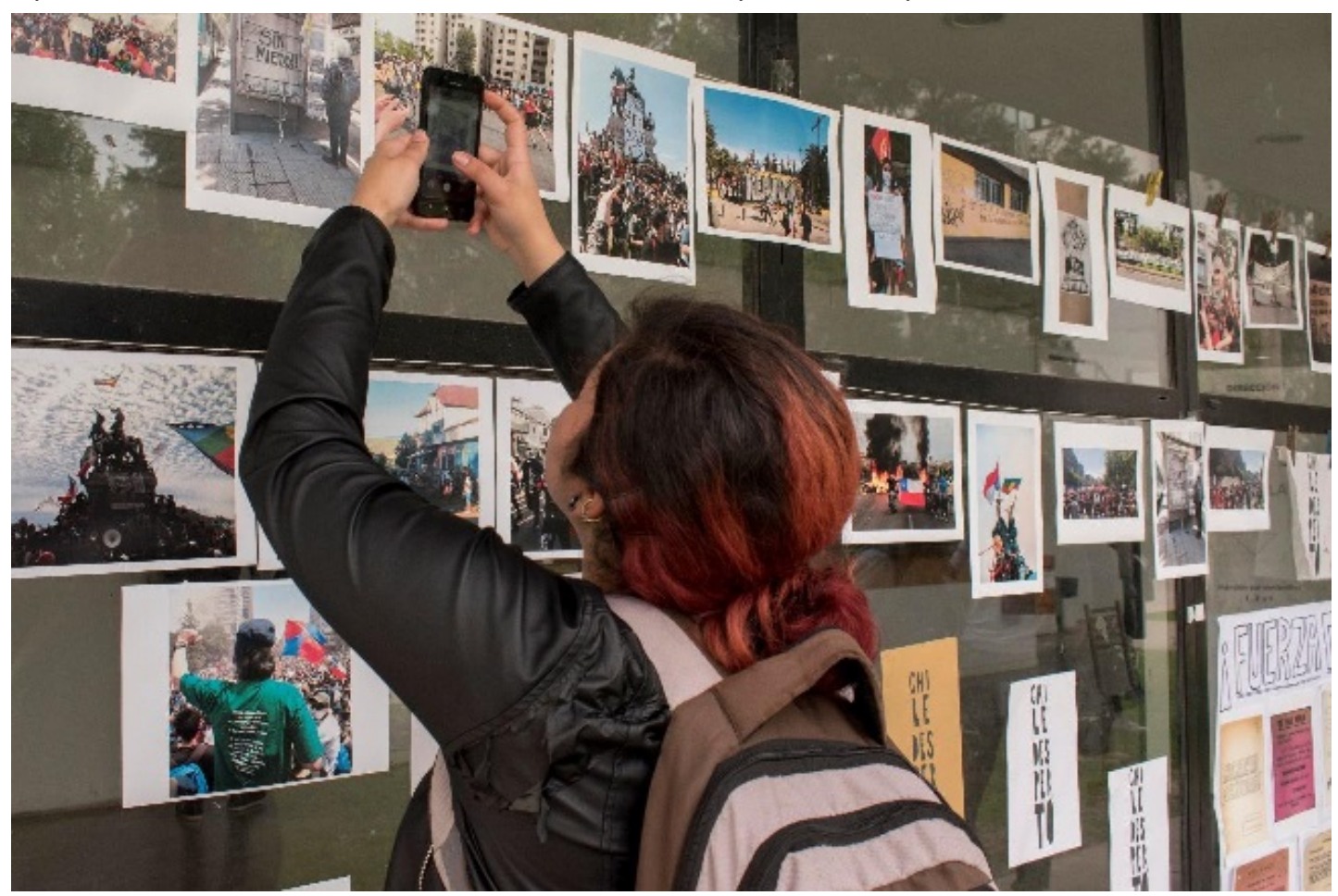

Fuente: Ana Sol Alonso

IMAGEN 4

Serigrafía "Chile despertó”. Diseño de Florencia Basso

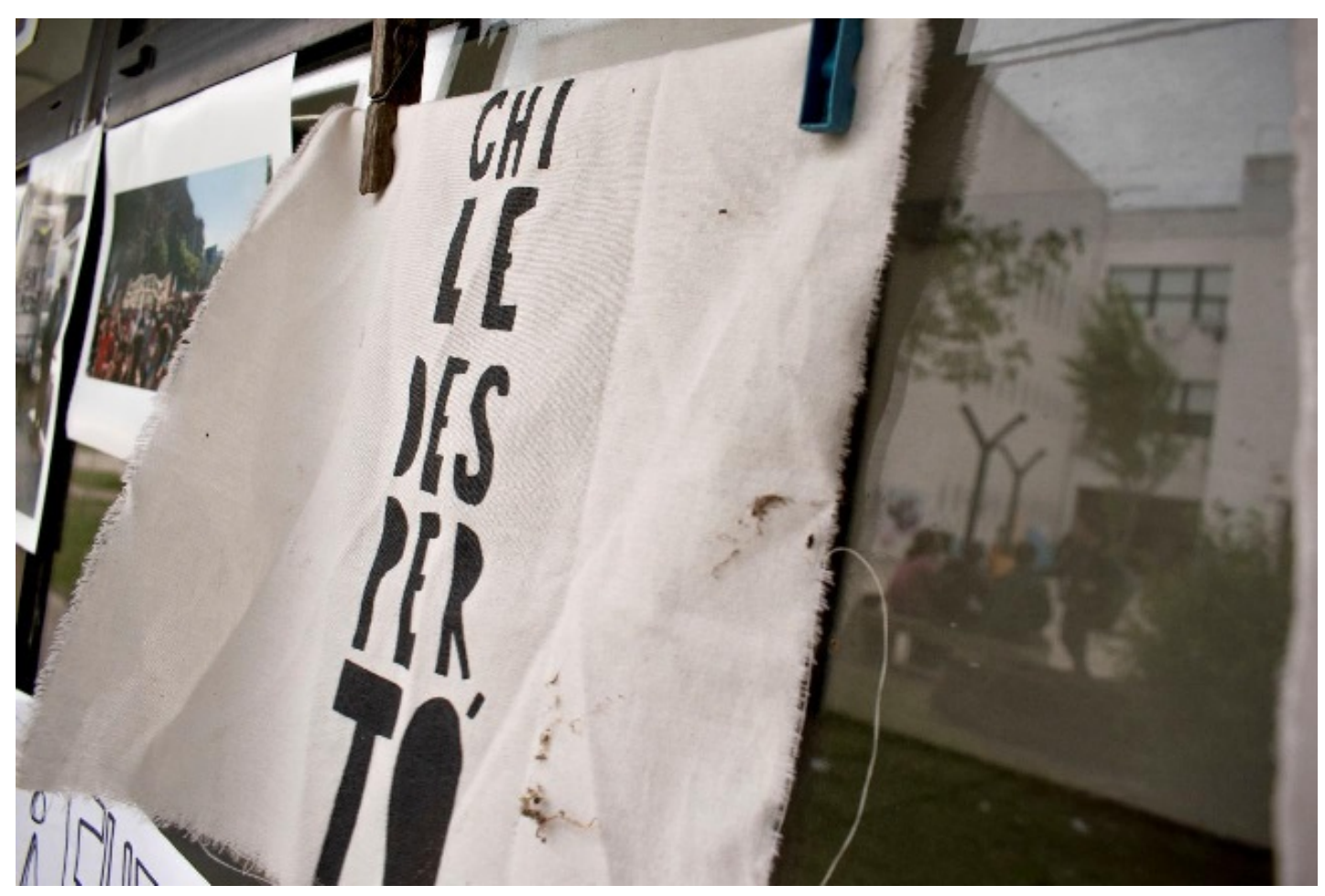

Fuente: Ana Sol Alonso 
IMAGEN 5

Serigrafía "No son 30 pesos, son 30 años”. Diseño de Emilia Nieto

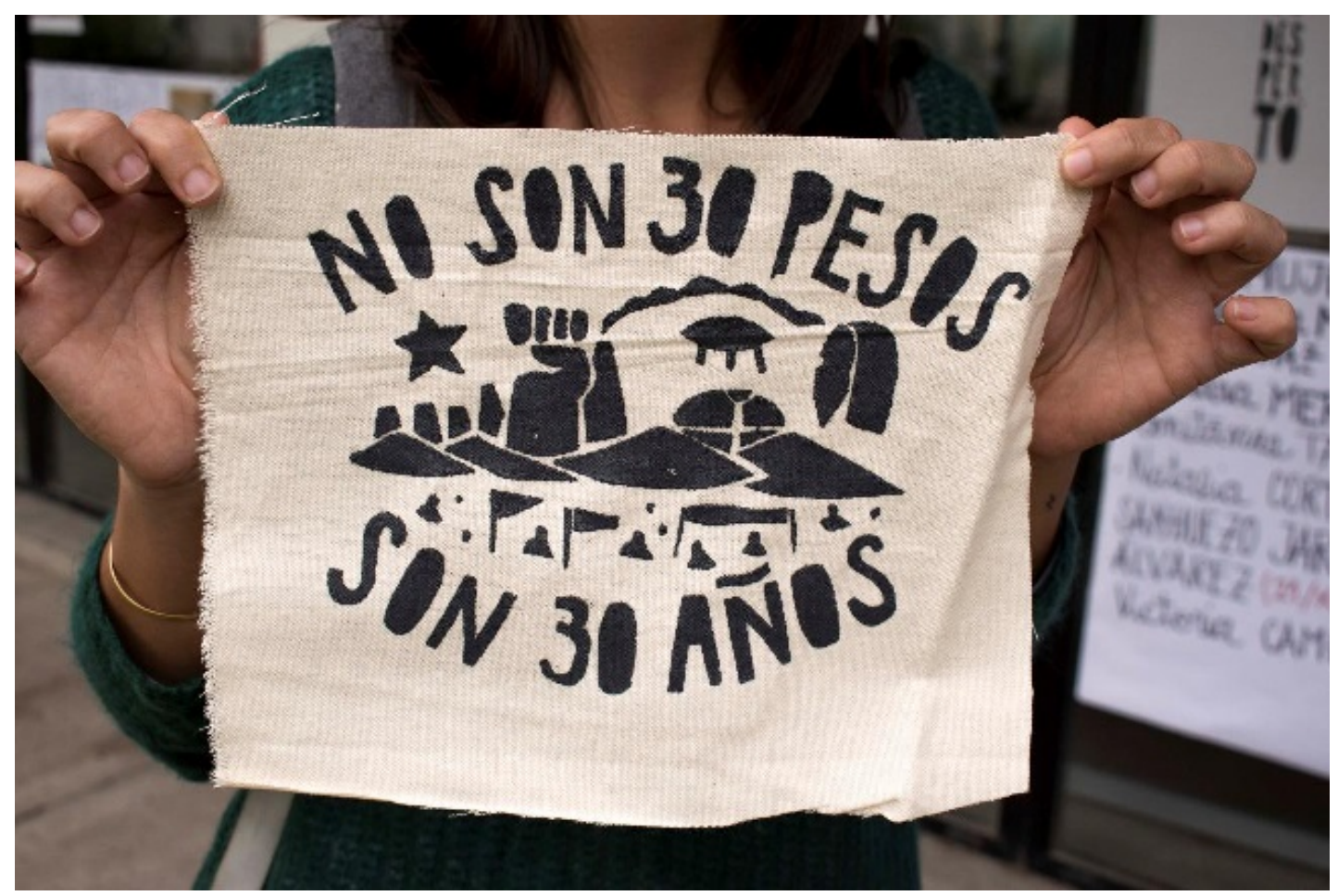

Fuente: Ana Sol Alonso

IMAGEN 6

Producción colectiva de serigrafías

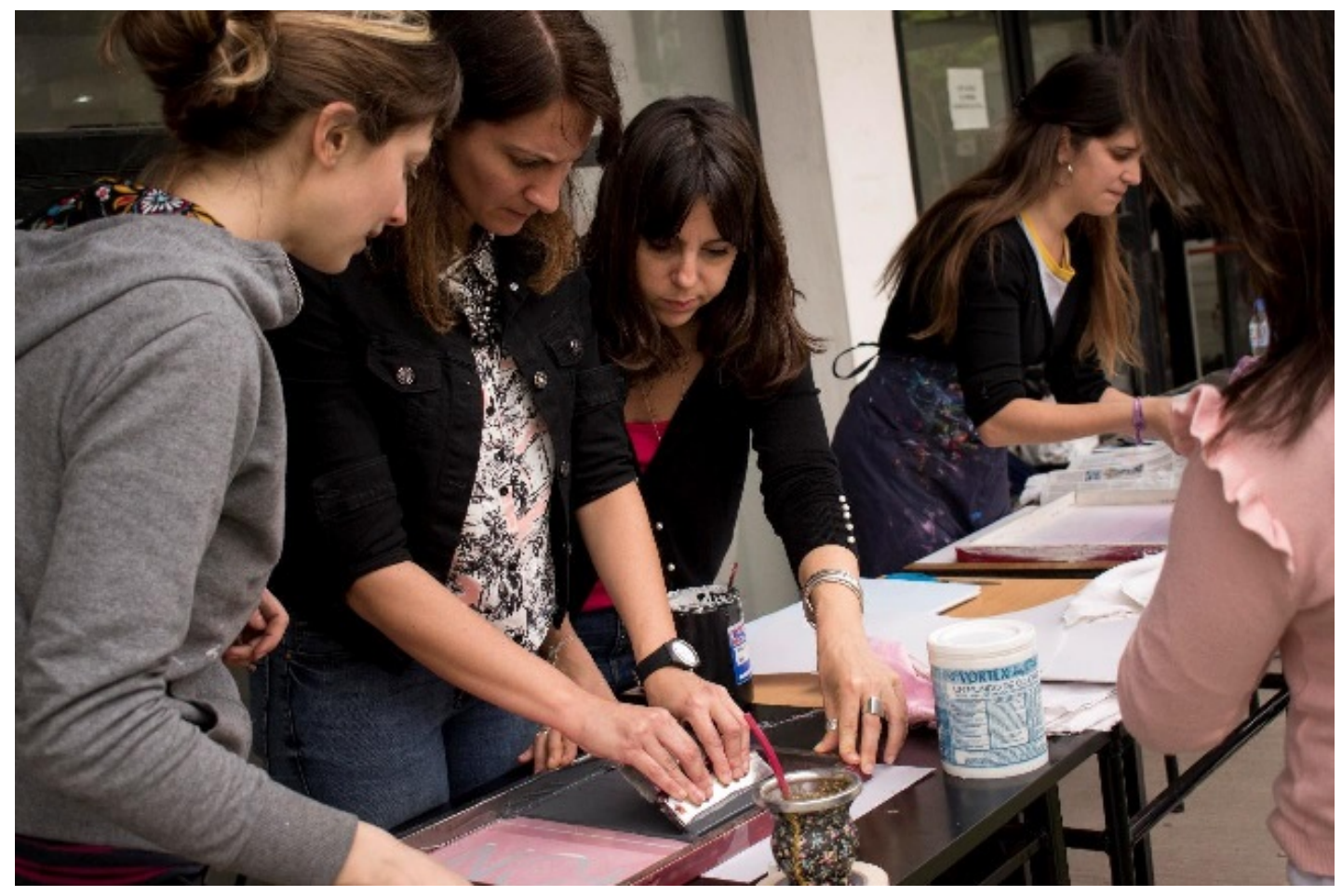

Fuente: Ana Sol Alonso 
IMAGEN 7

Producción de carteles informativos

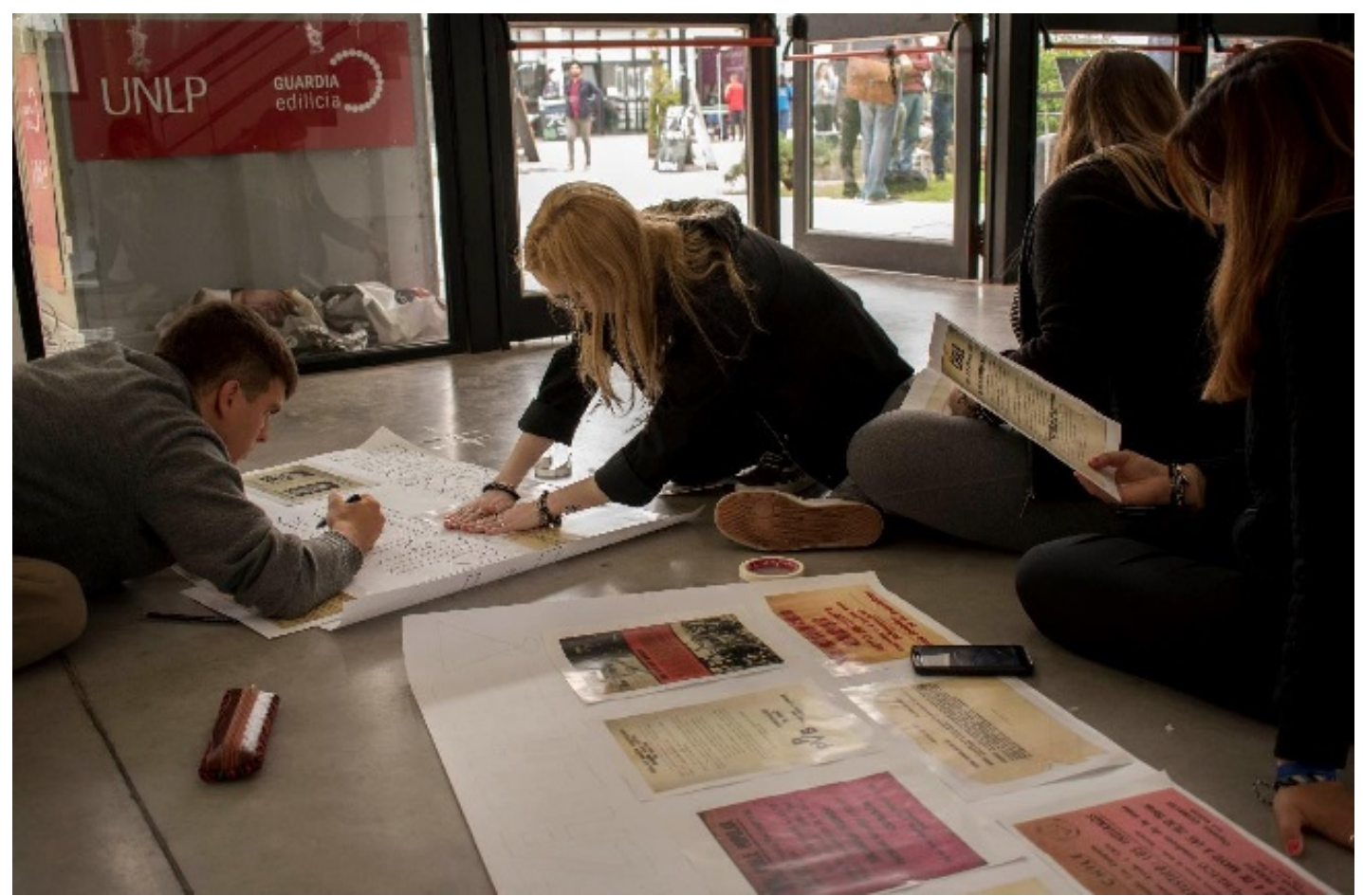

Fuente: Ana Sol Alonso

IMAGEN 8

Exposición de copias de documentos de los comités de solidaridad con Chile (COMACHI) de 1973 y 1974 reunidos por la Dirección de Inteligencia de la Policía de la Provincia de Buenos Aires, gentilmente cedidos por la Comisión Provincial por la Memoria, Archivo de la ex DIPPBA

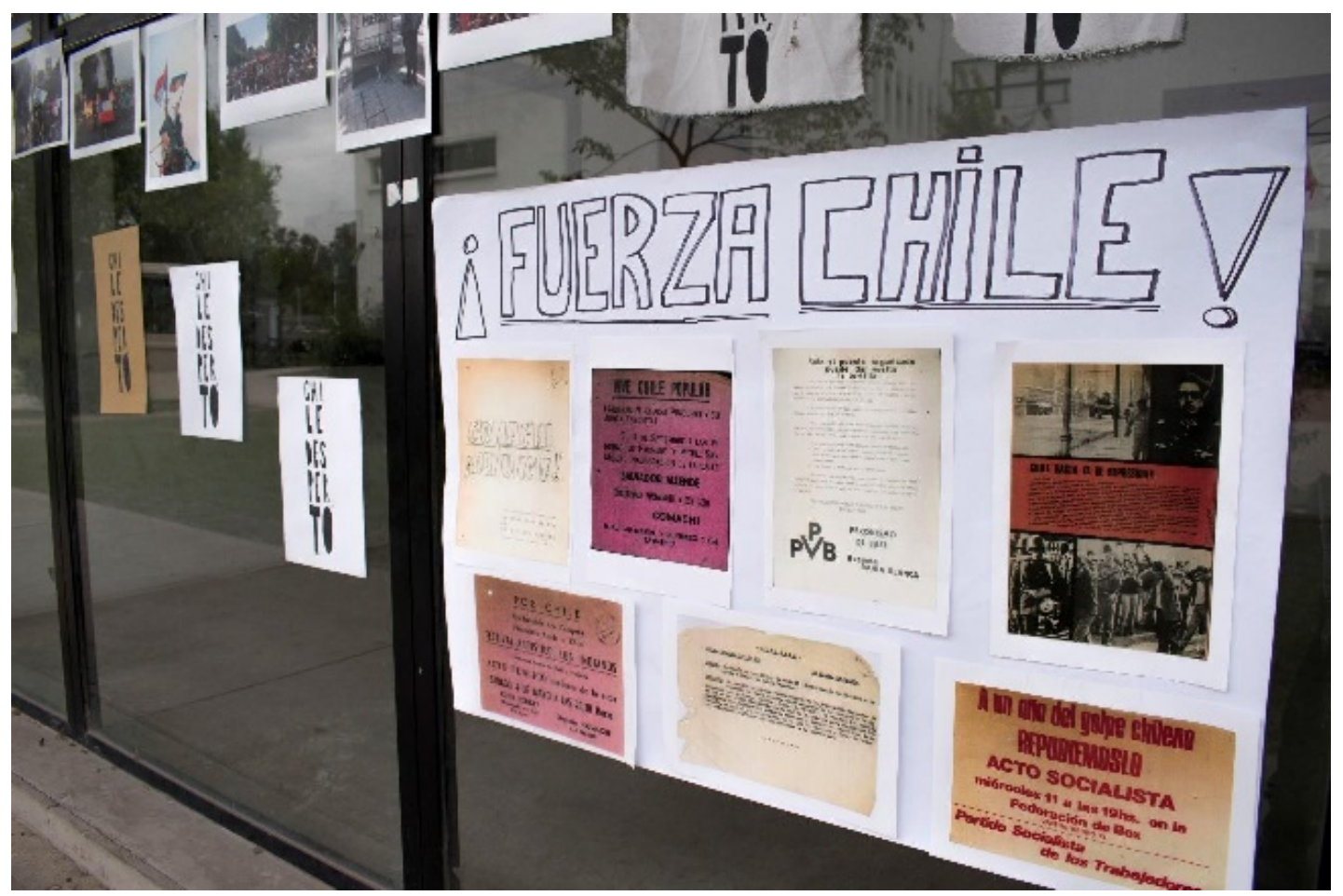

Fuente: Ana Sol Alonso 
IMAGEN 9

Producción de carteles informativos

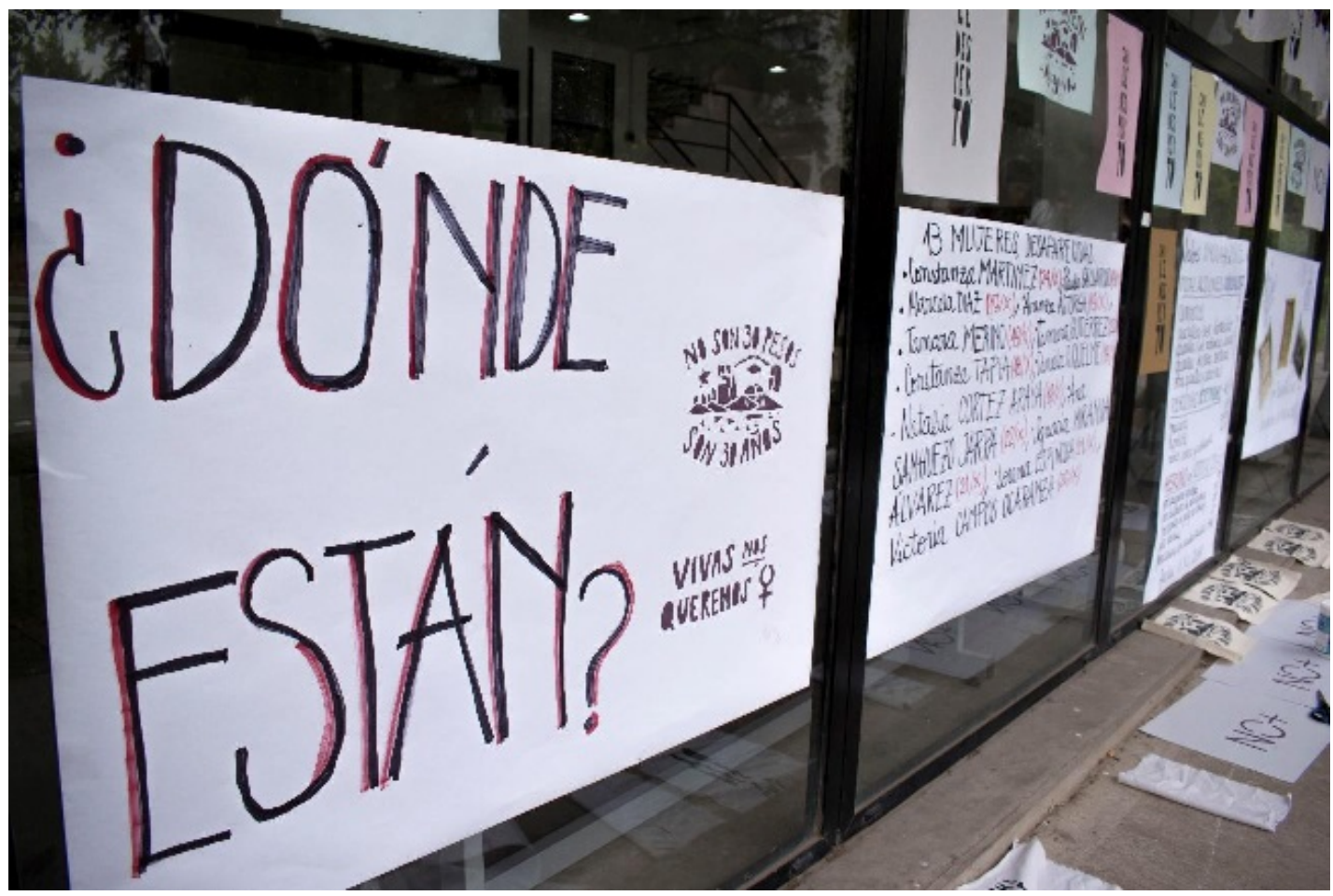

Fuente: Ana Sol Alonso

Por último, hacia el final se realizó una performance que fue registrada y editada por Fedra Delmas, Licenciada en Artes Audiovisuales de la Facultad de Artes (UNLP), que además generosamente también editó un hermoso video de toda la jornada:

Performance "NO+”. Filmación y edición: Fedra Delmas: https://www.youtube.com/watch?v=Woy $40 \mathrm{OsGycQ}$

Registro audiovisual de la Primera Jornada de visibilidad y solidaridad con Chile. Filmación y edición: Fedra Delmas: https://www.youtube.com/watch?v=m1Xj3ygMspU\&feature=emb_title

\section{SEgunda JornADA: ChILE, IMÁgENES DE LA INSURgENCIA}

Con el correr de los días, el impacto visual de todo el material de registro que nos iba llegando desde Chile -a través de las redes sociales y de nuestrxs colegas- fue muy fuerte y decidimos apostar a más. Nos preguntamos ¿cómo nos interpela desde nuestro ámbito académico la producción masiva de imágenes y videos en esta coyuntura? ¿Cómo pensar y colaborar colectivamente sobre la urgencia de estos acontecimientos desde nuestros espacios de trabajo en Argentina? "Pensar desde la urgencia” fue la primera inquietud que movilizó la organización de una jornada académica sobre las visualidades del estallido social. Dijo Cora Gamarnik en su presentación: "pensar sin que nos estén gaseando, sin que nos estén torturando, sin que nos estén violando, sin ver que esto está sucediendo en la esquina de nuestras casas” recordando así, anteriores formas de solidaridad emergentes de procesos sociales, como lo sucedido durante la dictadura chilena con el accionar de los grupos en el exilio y las denuncias y solidaridades internacionales. El objetivo, entonces, fue hacer un aporte al pensamiento y análisis crítico de lo que estábamos observando a la distancia, con más calma, estableciendo intercambios con nuestrxs colegas chilenxs y que en definitiva, todo esto sirviera como un insumo más para ellxs. El 12 de diciembre de 2019, en el edificio Karakachoff de la 
UNLP, se realizó esta Jornada de panel y debate en el marco del Día Internacional de los Derechos Humanos (conmemorado el 10 de diciembre) que denominamos "Chile, imágenes de la insurgencia" (Imagen 10).

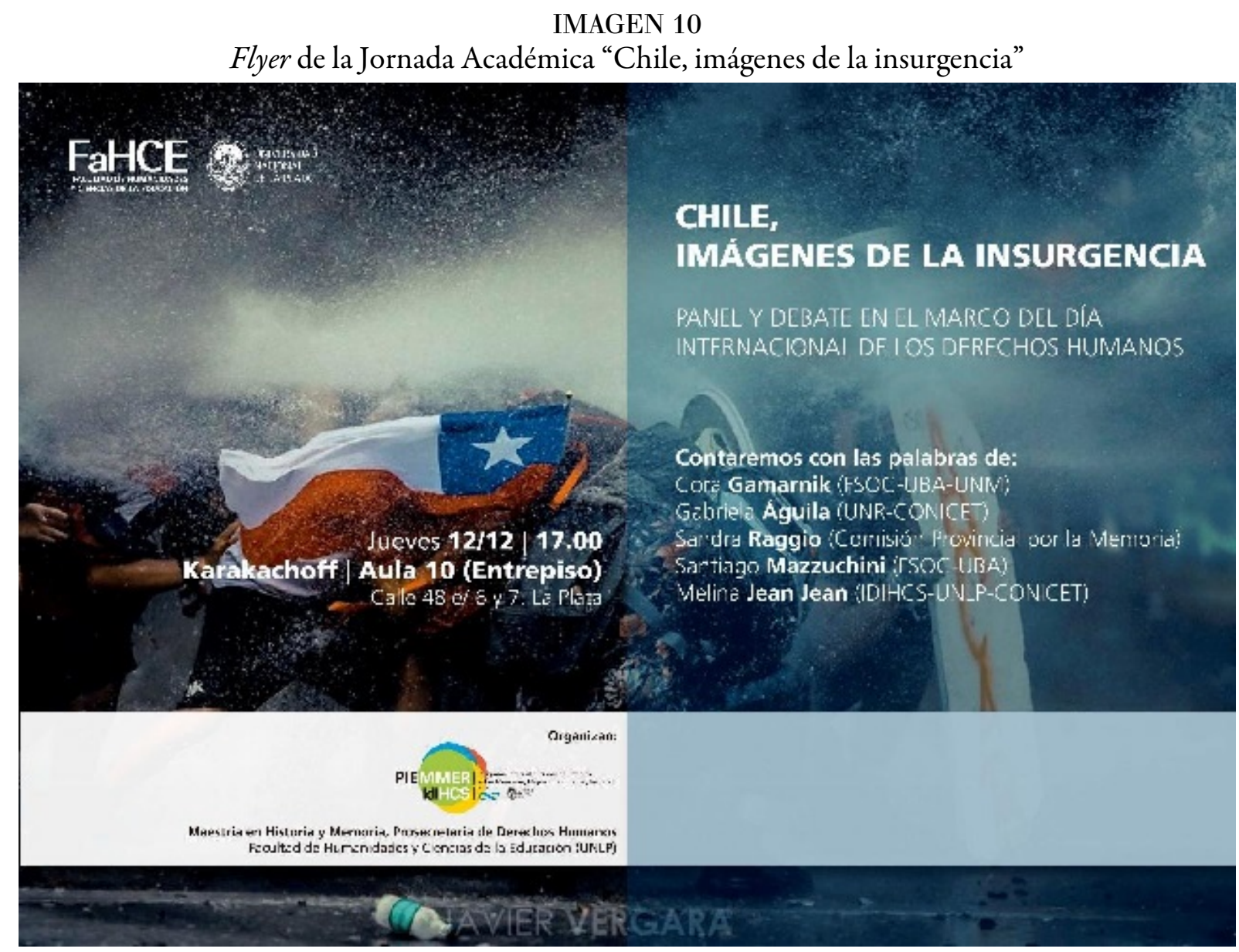

La potente imagen captada por el fotógrafo Javier Vergara, sintetiza la lucha y la resistencia contra la represión, no sólo de la Primera Línea sino de todo el pueblo chileno movilizado. Diseño: Área de Comunicación Visual, FaHCE, UNLP.

Lucía Abbattista, coordinadora de la Prosecretaría de Derechos Humanos de la FaHCE, fue la encargada de abrir la jornada e inaugurar el panel de debate. Luego de explicar los motivos del encuentro y reseñar las actividades realizadas en la primera jornada, presentó a lxs panelistas: Cora Gamarnik, Doctora en Ciencias Sociales y Coordinadora del Área de Estudios sobre Fotografía de la Facultad de Ciencias Sociales y del Programa de Actualización en Fotografía y Ciencias Sociales de la UBA; Gabriela Águila, Doctora en Historia, Profesora titular en la Universidad Nacional de Rosario (UNR) e Investigadora de CONICET; Sandra Raggio, Directora General de Áreas de la Comisión Provincial por la Memoria, Magíster en Ciencias Sociales, Profesora de Historia e Investigadora de la FaHCE, UNLP; Santiago Mazzuchini, Licenciado y Profesor en Ciencias de la Comunicación de la Facultad de Ciencias Sociales de la UBA y Diplomado en Educación, Imágenes y Medios en la Cultura Digital de FLACSO; Melina Jean Jean, Magíster en Historia y Memoria de la FaHCE y Licenciada y Profesora en Historia del Arte de la Facultad de Artes, UNLP.

Lista de reproducción completa de la Jornada "Chile, imágenes de la insurgencia": https:// www.youtube.com/playlist?list=PL62TU-kHYGHEDR_waX4Pds9E7e37sTgzJ

Las imágenes fueron el eje de análisis y discusión de la jornada. Sin embargo, debíamos pensarlas en su contexto de modo que decidimos previamente trabajar dos ejes más: la represión y los derechos humanos. Para ello, en primer lugar Gabriela Águila, como especialista en Historia Latinoamericana del siglo XX y en 
particular de la última dictadura, y del ejercicio de la represión en la Historia Reciente de Argentina, articuló su propuesta en pensar la violencia represiva política y estatal desde una perspectiva histórica de temporalidad a largo plazo, que permitiera comprender los acontecimientos en curso. En este sentido, se focalizó en los problemas de la violencia estatal y represiva en Chile, revisando la historiografía chilena, retomando a investigadorxs y colegas que trabajaron y trabajan sobre esta cuestión y con quienes ha intercambiado lecturas y opiniones al respecto. Entre otros temas, se refirió más a las continuidades que a las rupturas entre la dictadura pinochetista y la postdictadura; al papel central -en la vida política de Chile- de los carabineros como fuerza policial militarizada, y en su autonomía en el ejercicio cotidiano de la violencia hacia ciudadanos/ as y de la represión a los conflictos sociales, huelgas y manifestaciones políticas; la criminalización de la protesta social; el rol de las fuerzas armadas en general; y la legalidad e ilegalidad de la represión. Finalmente, mencionó los distintos momentos y las nuevas modalidades y combinaciones del despliegue represivo durante el estallido social de octubre.

Presentación de Lucía Abbattista y Gabriela Águila: https://www.youtube.com/watch?v=L62TQVH B1HE

Por su parte, Sandra Raggio nos invitó a pensar lo que estaba sucediendo en Chile desde la perspectiva de los derechos humanos, a partir de presentarnos diversas modalidades de la represión estatal, advirtiéndonos en primer lugar, de la "falacia" de que la represión y las violaciones a los derechos humanos solo está vinculada a dictaduras. Propuso revisar a "contrapelo" aquellas construcciones que delimitan un corte entre dictaduras y democracias y que establecen así, un imaginario falso de que en democracia las violencias estatales ocurren de manera episódica, como excesos o asuntos pendientes a resolver. Se trata entonces de pensar, partiendo de lo que nos muestra la situación en Chile, la violencia estatal de manera estructural, para dar cuenta de la naturaleza del Estado democrático, o bien de pensar cómo se construyeron las democracias post dictaduras y qué rol adquirieron las fuerzas de seguridad en la garantía del orden social.

Presentación de Sandra Raggio: https://www.youtube.com/watch?v=Xp-FjObOG2M

\section{IMÁgenes, REFLEXIONES Y TESTIMONIOS DESDE CHILE}

A continuación de estas dos intervenciones, comenzamos a pensar las visualidades y decidimos hacerlo compartiendo el material que nos llegó desde Chile exclusivamente para esta jornada. En primer lugar, proyectamos el audiovisual de la Colectiva somoslacélula de lxs investigadorxs y activistas Ángeles Donoso Macaya y César Barros, titulado "Voltear la cabeza de Chile". A través de un escrito, nos contaron que frente a la infinitud de imágenes que circularon tanto en redes sociales como en diferentes medios online, les pareció oportuno ofrecer una reflexión en clave histórica sobre una sola imagen, una captura que apareció en el sitio web del canal 13, tomada de un video que circuló en las redes sociales. La imagen registra una acción que se repitió en varias ciudades del país: la intervención o el derrumbamiento de estatuas de figuras históricas, como en este caso la del "conquistador" Pedro de Valdivia en la ciudad de Concepción. En el audiovisual sus creadorxs aluden a las condiciones de creación del estado nación de Chile y a la "identidad chilena", "una identidad que para enaltecer la masacre colonial y ensalzar a los asesinos europeos solo glorifica a los guerreros indígenas de antaño cuando le conviene, mientras masacra y acusa de terroristas a quienes reivindican en el presente, el modo de vida de aquellos valientes". De esta forma, destacan a las comunidades indígenas, su herencia y sus luchas, que han sido invisibilizadas en la historia enseñada de Chile y es justamente "esa historia que hay que voltear de cabeza".

Presentación de la Colectiva somoslacélula: https://www.youtube.com/watch?v=zG7SKT3ayPM

En segundo lugar, Alicia Salomone, Doctora en Literatura y Profesora Titular del Departamento de Literatura y del Centro de Estudios Culturales Latinoamericanos de la Facultad de Filosofía y Humanidades de la Universidad de Chile, envió un video donde pudimos ver y escuchar sus reflexiones sobre tres imágenes testimoniales de la revuelta, que considera representativas de la encrucijada actual de su país: por un lado, la 
declaración de guerra del gobierno de Piñera contra su propio pueblo y el horror de la represión, y por el otro, las escenas de esperanza de una "ciudadanía que quiere hacerse dueña de su destino".

Presentación de Alicia Salomone: https://www.youtube.com/watch?v=msxepNMmndA

A continuación, presentamos una serie de imágenes titulada "Cuerpos rebeldes, colectivos y sororos: la fuerza feminista en el espacio público del Estallido social en Chile" de Mane Adaro, curadora independiente e investigadora y directora de la revista de fotografía ATLAS. Su selección de fotografías nos muestra el cuerpo feminista en el desarrollo de la protesta y la denuncia de la violencia y los abusos del Estado contra las mujeres. Pudimos ver entonces, desde aquellas mujeres que se han unido como cuerpo de lucha a la Primera Línea, a expresiones, intervenciones y performances callejeras como el caso del colectivo La Yeguada Latinoamericana, el de la artista y activista anti-gordofobia Rocío Hormazábal, y la canción y baile del colectivo Las tesis.

Presentación de Mane Adaro: https://www.youtube.com/watch?v=TJfP0x-WH8U

Por otra parte, el Colectivo foto-documental Migrar Photo nos envió un audiovisual que a través de una edición compilatoria de fotografías, videos, sonido (de los cacerolazos) y palabras, nos muestran las movilizaciones, la creatividad de lxs manifestantes, las declaraciones de Piñera, el despliegue de carabineros y del Ejército, la represión y lxs heridxs. El mensaje final es "DESPERTAMOS”. Karina Aliaga, integrante del colectivo, estuvo presente en la jornada y nos contó que el grupo está conformado por fotógrafxs, periodistas, cineastas y psicólogxs de diversas regiones de Chile, y que su objetivo es contribuir a que las imágenes que circulan en la web a través de fotografías y videos, se difundan en otros formatos y puedan ser pensadas y discutidas.

Presentación de Migrar Photo:https://www.youtube.com/watch?v=8rhVHCIRMx4

Luego de esta intervención, contamos con la presencia de la periodista chilena Claudia Arándalo y la fotógrafa y corresponsal argentina Paula Acunzo, ambas recientemente llegadas de Chile, quienes nos brindaron su testimonio sobre lo que habían vivido en primera persona durante las movilizaciones. Claudia nos relató parte de su experiencia durante la cobertura nocturna bajo el toque de queda en Santiago, y el momento en que fue violentamente detenida por carabineros cuando presenciaba la detención ilegal de dirigentes estudiantiles secundarios. También sobre como posteriormente colaboró en el registro de detenciones a periodistas, reporteros gráficos y de diversos medios. Paula, por su parte, estuvo trabajando junto a la Primera Línea, de modo que su relato sobre la represión -acompañado por algunas de sus fotografíasfue muy detallado. Ella misma sufrió no solo la violencia de carabineros, sino también la censura, pues en reiteradas ocasiones intentaron apagar su cámara. Ambas aseveraron que lo vivido fue una guerra del Estado contra su pueblo, un Estado decidido a reprimir, castigar, torturar, desaparecer y asesinar.

Presentaciones de Claudia Arándalo y Paula Acunzo:https://www.youtube.com/watch?v=I7qbqJgVx iQ

Para terminar con esta serie de presentaciones, proyectamos "Chile despertó" una serie de fotografías en blanco y negro que nos envió el multipremiado fotógrafo argentino Pablo Piovano, tomadas durante el mes de octubre en Santiago. Las imágenes relatan diversos momentos del estallido a partir de diferentes encuadres, enfoques, ángulos y objetos.

Fotografías de Pablo Piovano http://www.pablopiovano.com/chile.html

\section{CierRe DE LA JoRNADA}

A continuación de las intervenciones de lxs colegas chilenxs, la jornada continuó con las presentaciones de lxs panelistas:

A mi cargo estuvo la presentación de una compilación de audiovisuales sobre la represión, una selección del registro que pude realizar durante mi observación online del material que circulaba en la web, particularmente en las redes sociales. Se trata de videos que filmaron manifestantes y también de aquellxs que desde sus casas 
o barrios, registraron el violento accionar de carabineros y el Ejército. En principio señalé el impacto por la cantidad y calidad de las filmaciones. Solo en aproximadamente quince días en el mes de noviembre, había logrado armar un archivo de 412 publicaciones. Los videos filmados desde celulares inteligentes captaron de manera contundente y como nunca antes la represión. En ellos no sólo se documentaba el nivel de la violencia y las distintas modalidades represivas, sino fundamentalmente el terror, el miedo, el dolor, la indignación de quienes valientemente sostuvieron su celular, en una situación absolutamente adversa y en la que su salud o su propia vida corría peligro. Además, propuse prestar atención a las cualidades de los elementos que componen el lenguaje audiovisual y que denotan las condiciones de producción y comunicación multisensorial: múltiples relatos en pocas secuencias, movimientos desprolijos y caóticos, encuadres, planos, campo (y fuera de campo) y ángulos vertiginosos. En cuanto al sonido: la superposición de voces, los tonos de voz, gritos, llantos, relatos de lo que acontece, testimonios de heridxs, diálogos, silencios, jadeos, insultos hacia las fuerzas de seguridad. Así como también aquellos propios de la represión: sirenas, golpes, tiros, órdenes, amenazas, agresiones verbales, entre otros. Todos son indicadores del horror vivido y las emociones de quien está filmando y quienes $\mathrm{lx}(\mathrm{s})$ acompañan. Se trata de pensar de manera relacional el contexto, el rol del actor que está filmando, el rol del celular como dispositivo, la difusión y circulación de los videos ante la falta de cobertura mediática, así como también su cualidad de documento o medio de prueba para la denuncia ${ }^{6}$.

Presentación de Melina Jean Jean: https://www.youtube.com/watch?v=GCrHwhZVAKc

Luego, Santiago Mazzuchini reflexionó sobre la circulación de las imágenes de la "sublevación" de Chile en las plataformas digitales, destacando el rol de los medios alternativos y contrainformativos que abogan por un periodismo comprometido y de intervención. A su vez, destacó que este tipo de imágenes toman posición haciendo visible aquello que los medios tradicionales no muestran. Particularmente, las que registran la revuelta, funcionan como contraimágenes: en ellas vemos los cuerpos sublevados y aquellos espacios que ocuparon interviniendo en la historia, no como mero instrumento o ilustración, sino como agentes, en tanto que detrás de las mismas hay cuerpos y personas que las producen. Por lo tanto, lo relevante, dice, es recuperar las historias y las memorias de las imágenes.

Presentación de Santiago Mazzuchini: https://www.youtube.com/watch?v=sI 18ZYLN-vo

Por último, Cora Gamarnik fue la encargada de cerrar la jornada. En principio agradeció fuertemente a todxs lxs colegas de Chile, que aún desde la urgencia, produjeron los maravillosos materiales que anteriormente reseñamos, y que además casi en su mayoría fueron exclusivamente hechos para esta ocasión. Este intercambio dijo Cora "tuvo que ver con entender desde adentro de Chile la necesidad de que salga material para que podamos devolverle algún análisis”. Retomando todo el derrotero de imágenes que vimos a lo largo del panel, reflexionó sobre la superabundancia y la circulación masiva de las mismas. Ante esa multiplicidad, propuso pensar en el ejercicio de seleccionar algunas de ellas para poder observarlas detenidamente, analizarlas e historizarlas y así conocer qué nos dicen sobre el régimen de visibilidad actual y los acontecimientos. Destacó la "dimensión visual de la lucha" y del "productor de imágenes" como "un eslabón central de estas movilizaciones" en tanto que en respuesta a las nuevas modalidades de represión creó nuevas formas de visibilidad (y también de identidad). En relación a esto, reflexionó sobre la "espectacularidad de la protesta" en Chile, construida como estrategia de visualidad ante la urgente necesidad de mostrar lo que estaba sucediendo. También habló de la "dimensión experiencial" de la lucha: el ir a la manifestación, participar, registrarla, pero sobre todo el hecho de prepararse y todo el trabajo previo de organización, que generan experiencias particulares, generan comunidades, lazos sociales e identidades. Por último, se concentró en analizar el rol de la fotografía fija en las protestas (su circularidad, reproducción infinita, potencia) y en plantear temas que necesitan ser debatidos como: las diferencias entre las fotografías "desde adentro" y aquellas tomadas "desde afuera", la emergencia de fotografías icónicas y el aporte de los memes en su perpetuación y circulación.

Presentación de Cora Gamarnik: https://www.youtube.com/watch?v=mBreCp3_dyk 
Durante la Jornada exhibimos nuevamente las fotografías de nuestrxs compañerxs chilenxs, y Florencia Basso y Emilia Nieto esta vez produjeron previamente serigrafías en sus propios talleres para luego compartirlas con nosotrxs (Imagen 11). Todo este material entonces, estuvo a disposición de lxs asistentes, panelistas y organizadorxs (Imagen 12). La filmación y transmisión en vivo a través de la página de Facebook de la Maestría, estuvo a cargo de Florencia Larralde Armas (egresada de la Maestría en Historia y Memoria e integrante del comité editorial de la Revista Aletheia) y Fernanda Tocho (Secretaria Académica de la Maestría en Historia y Memoria y coordinadora editorial de la Revista Aletheia). La edición y difusión, a cargo de quien escribe.

\section{IMAGEN 11}

Serigrafías de Florencia Basso "Chile Despertó” y Emilia Nieto "Chile Resiste”. Exhibición de fotografías tomadas durante las movilizaciones por compañerxs, graduadxs y estudiantes chilenxs de la Maestría en Historia y Memoria y el Doctorado en Historia

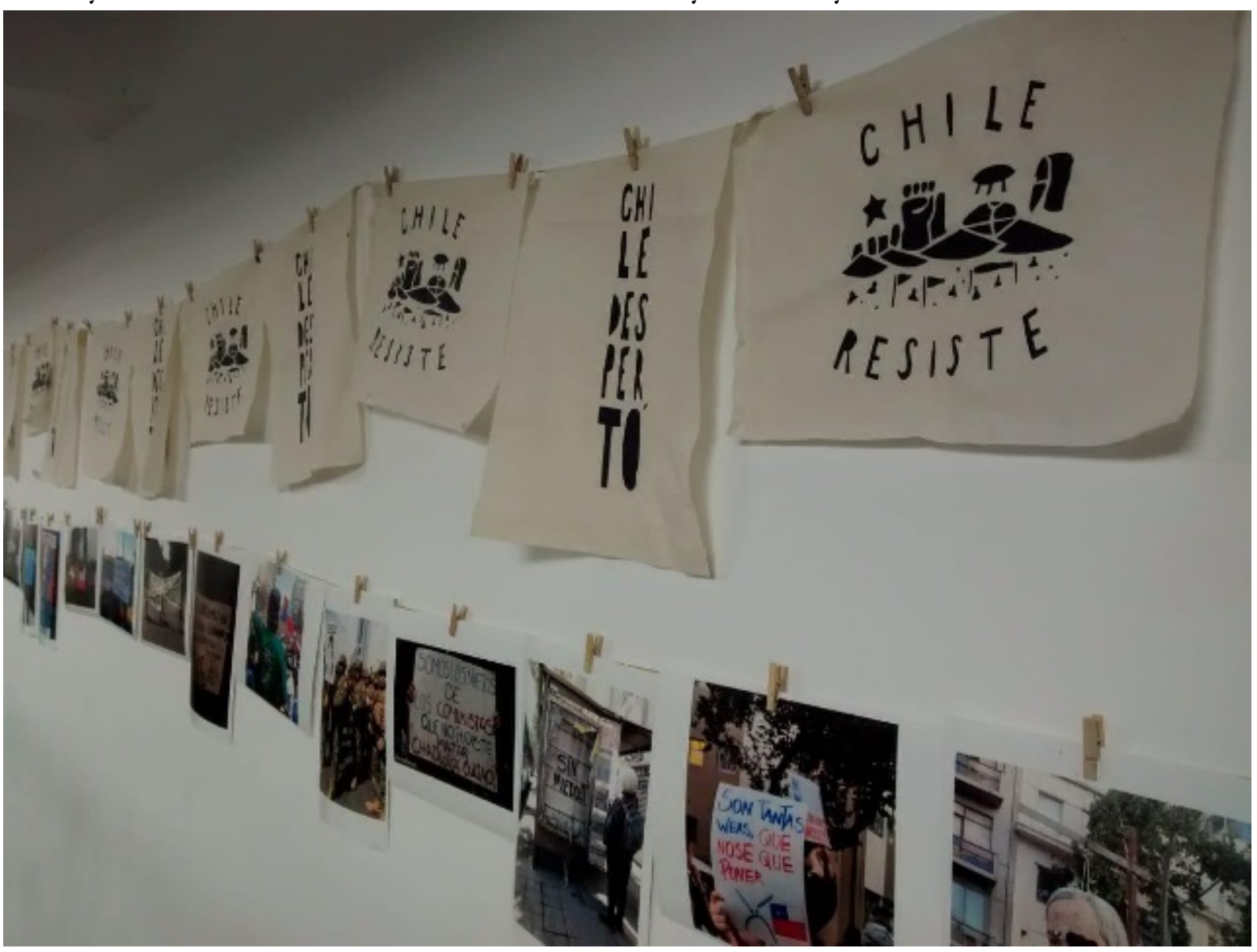

Fuente: Melina Jean Jean 


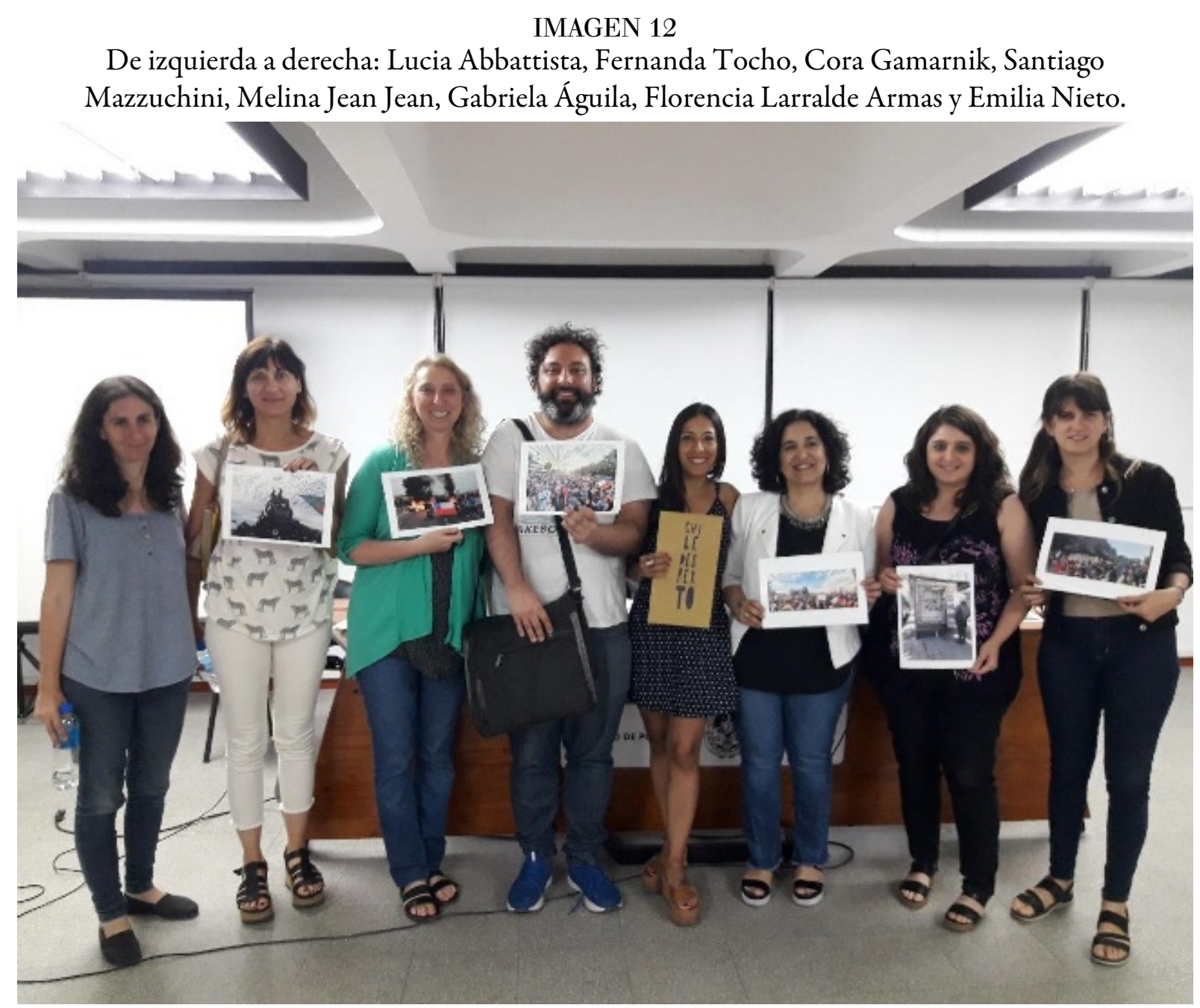

Finalmente, no podemos dejar de mencionar la última acción que realizamos desde nuestra querida Maestría en el mes de diciembre. En respuesta a la convocatoria "Proyecto Postales Chile" del Museo de la Memoria y los Derechos Humanos de Santiago, Emilia Nieto diseñó una hermosa y sentida postal que manifestó nuestro apoyo al pueblo chileno como pedía la consigna (Imagen 13). Todas las postales de este proyecto serían exhibidas en el Museo. 
IMAGEN 13

Postal “CHILE RESISTE. Hasta que la dignidad se haga costumbre” diseñada por Emilia Nieto

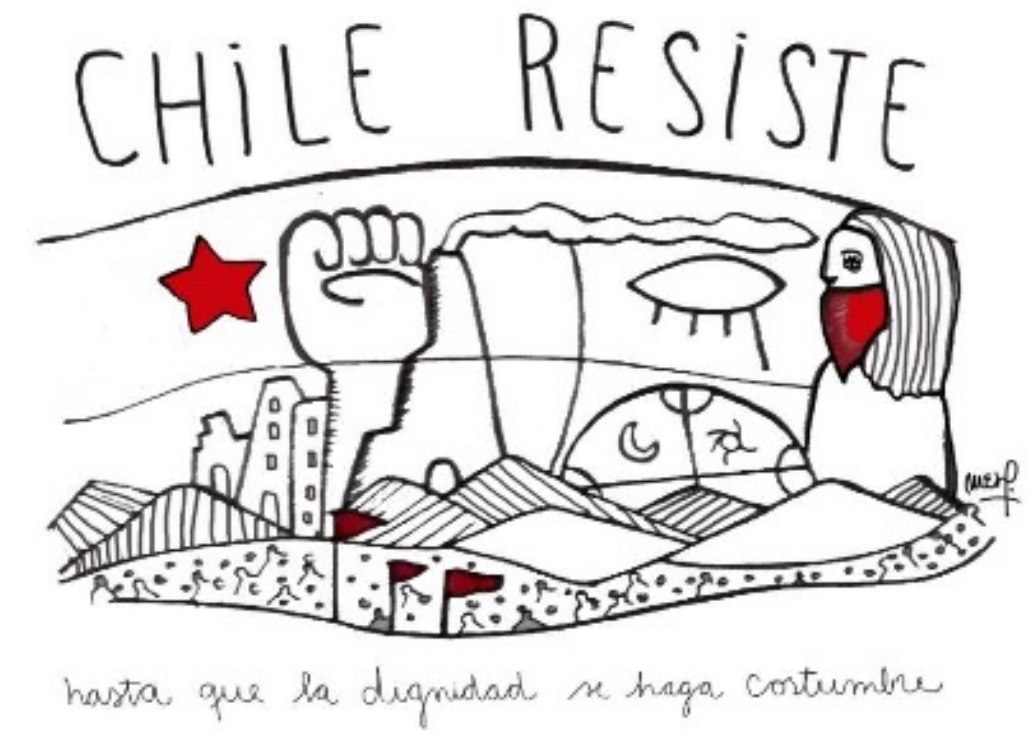

Maestría en Historia y Memoria - UNLP - Ensenada, Bs. As., Argentina - Diciembre 2019

Participación de la Maestría en Historia y Memoria en la convocatoria del "Proyecto Postales Chile” del Museo de la Memoria y los Derechos Humanos de Santiago, Chile. Diciembre de 2019

\section{ReFERENCIAS}

"Estamos en Guerra": Piñera en busca del enemigo interno", (21 de octubre de 2019). ANred. Recuperado de: https:/ /www.anred.org/2019/10/21/estamos-en-guerra-pinera-en-busca-el-enemigo-interno/

Jean Jean, M. (2019). ““Chile despertó”. Visualidades emergentes en la lucha y resistencia del pueblo movilizado”. Artefacto visual 4 (7), Madrid, Red de Estudios Visuales Latinoamericanos, pp. 133-140. Recuperado de: https://5551dd67-1da1-4c54-bcb6-7ab3b18e5b71.filesusr.com/ugd/5373fb_9ec80b5b5bac43baaae1a651 8af47e8e.pdf

Monzón, C. "'Nuestro país es un verdadero oasis": la frase de Piñera que es recordada por la prensa española tras estallido social" (20 de octubre de 2019). Publimetro. Recuperado de: https://www.publimetro.cl/cl/social/20 19/10/20/pinera-chile-crisis-estallido-social-santiago-oasis-latinoamerica-el-pais-redes-sociales.html

\section{Notas}

1 La denuncia de la desigualdad en Chile podría decirse es la base y un punto de partida para comprender las demandas sociales de este país. Según la última edición del informe Panorama Social de América Latina 2019 elaborado por la Comisión Económica para América Latina y el Caribe (CEPAL) presentado en enero de ese mismo año, el 1\% más adinerado de Chile se quedó con el 26,5\% de la riqueza en 2017 , mientras que el $50 \%$ de los hogares de menores ingresos accedió solo al 2,1\% de la riqueza neta del país (Paúl, F. "Protestas en Chile: 4 claves para entender la furia y 
el estallido social en el país sudamericano" (23 de octubre 2019) BBC News Mundo. Recuperado de: https://www.b bc.com/mundo/noticias-america-latina-50115798). El movimiento social reclama, entre otras importantes demandas: una reestructuración de base socioeconómica; una Asamblea Constituyente y Nueva Constitución; aumento del salario mínimo; modificación del sistema tributario y el sistema privado de pensiones, no más Administradoras de Fondos de Pensiones (AFP); salud y educación gratuita y de calidad; nacionalización de empresas sanitarias y del agua.

2 Véase: Abbattista, L.; Conejo, Y.; Lastra, S. (2015) “Introducción” y Jean Jean M. (2015) “Ayotzinapa somos tod@s” en Cuadernos de Aletheia $N^{\circ} 1$ Ayotzinapa: reflexiones sobre la violencia desde Latinoamérica, 5 (10) 2-7 y 37-40. Recuperado de: http://aletheiaold.fahce.unlp.edu.ar/numeros/numero-10/pdfs/Cuadernos\%20de\%20Aletheia\%20OK..pdf

3 Véase: Jean Jean, M., y Raina, A. (2017). Reseña e imágenes “No fue el Fuego, fue el Estado”; Facultad de Humanidades y Ciencias de la Educación de la UNLP. Aletheia, 7(14), 1-6. Recuperado de: https://www.aletheia.fahce.unlp.edu.ar/ article/view/ATHv7n14a12

4 Véase: Maestría Historia Memoria “Jornada Solidaria por Colombia”, 21 de noviembre de 2019. Recuperado de: https ://www.facebook.com/maestriahistoria.memoria/posts/2479440055670162

5 Véase: Maestría Historia y Memoria “Solidaridad con Chile”, 2 de diciembre de 2019. Recuperado de: https://www.fa cebook.com/maestriahistoria.memoria/posts/2489752651305569

6 De hecho, este tipo de audiovisuales sirvieron como pruebas para las denuncias por violaciones a los derechos humanos de organizaciones como Amnistía Internacional y Human Right Watchs. 